\title{
Mass balance of Himalayan glaciers using AAR and ELA methods
}

\author{
ANIL V. KulKarni \\ Marine and Water Resources Division, Space Applications Centre (ISRO), Ahmedabad 380 053, India
}

\begin{abstract}
The accumulation area ratio (AAR) for Himalayan glaciers representing zero mass balance is substantially lower than for North America and Europe. Regression analysis suggests 0.44 for the AAR representing zero mass balance in the western Himalaya. A good correlation was observed when this method was applied to individual glaciers such as Gara and Gor-Garang in Himachal Pradesh, India. The correlation coefficients $(r)$, using 6 and 7 years of data, respectively, were 0.88 and 0.96 for Gara and Gor-Garang Glaciers, respectively. However, when data from six western Himalayan glaciers were correlated, the correlation was 0.74 . The AAR was also estimated by using Landsat images which can be useful in obtaining a trend in mass balance for a large number of Himalayan glaciers for which very little information exists.

A higher correlation was observed between equilibrium-line altitude (ELA) and mass balance. The field data from Gara and Gor-Garang Glaciers shows a high correlation coefficient, i.e. -0.92 and -0.94 , respectively. The ELA values obtained from the Landsat satellite images combined with topographic maps suggest positive mass balance for the year 1986-87 and negative for 1987-88.
\end{abstract}

\section{INTRODUCTION}

Glacier mass-balance studies are gaining attention in India as development activities are increasing in the Himalaya. In the near future, many micro- and minihydro-electric power stations are planned, where the main source of water is glacier meltwater and seasonal snowmelt run-off. Therefore, mass balance would be an important input to assess long-term availability of water.

In India, field-based glacier mass-balance data are available for very few glaciers, and their availability is restricted only to a few years. This is mainly because of the rugged Himalayan terrain. Therefore, approximate estimates are essential to assess mass balance for glaciers where field data are not available. In this context, appplicability of accumulation-area ratio and equilibrium-line-altitude methods are discussed in this paper.

\section{DATA SOURGE AND STUDY AREA}

In this investigation, field data related to mass balance, equilibrium line, accumulation area and ablation area were collected from various sources. Field data for Tipra Bank, Gara, Gor-Garang and Neh-Nar Glaciers are taken from various unpublished reports of the Geological Survey of India (GSI) and Raina and others (1977), for Kolahoi and Shishram Glaciers from Kaul (1986), and for Chhota Shigri Glacier from Kulkarni (1988).

In these investigations, glacier mass balance was estimated by using glaciological methods. For example, at Gor-Garang Glacier, a network of 42 stakes over an area of $2 \mathrm{~km}^{2}$ was established. Ablation data were obtained by monitoring individual stakes and comparing glacier-ice or snow positions with previous years. These observations are normally carried out at the end of the snow-ablation season. Snow accumulation is estimated by

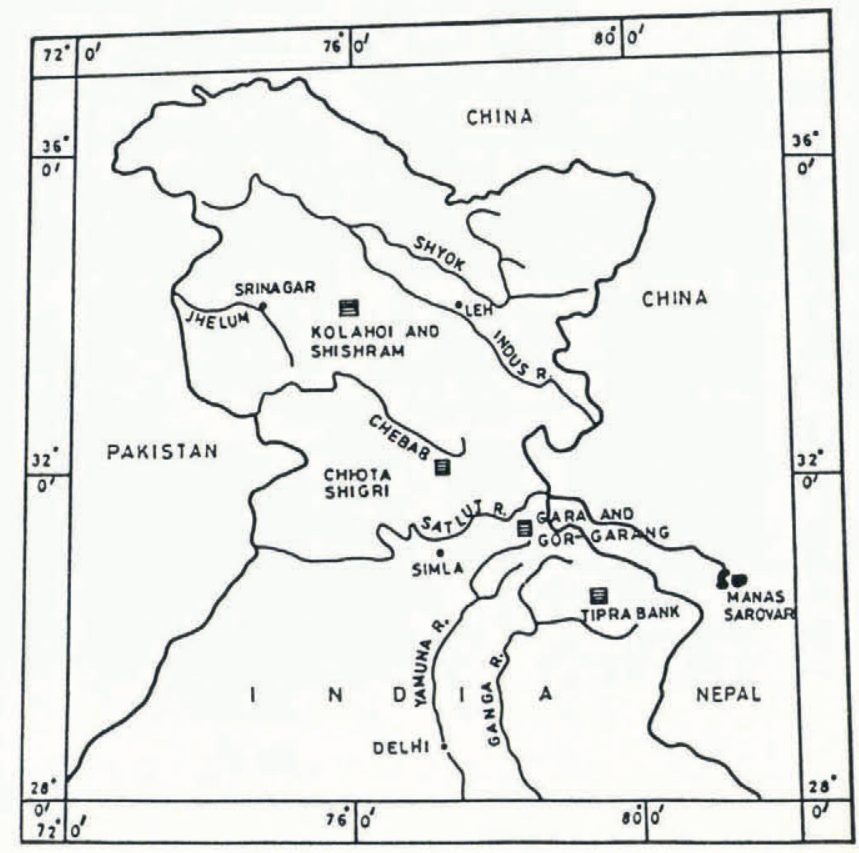

Fig. 1. Location map of the western Himalayan glaciers. 
using stake readings and snow-pit data at a number of points in the accumulation area. In addition, snow- and ice-ablation data are also measured at intervals of $15 \mathrm{~d}$ from the middle of July to the end of August. Similar observations were also made at other glaciers as Chhota Shigri, Gara and others. Locations of these glaciers are given in Figure 1. These glaciers are well distributed in the region of the western Himalaya; i.e. west of Nepal.

\section{VARIATION IN MASS BALANCE WITH AAR}

AAR is the ratio of accumulation area to the total area of the glacier (Meier, 1962). Meier and Post (1962) suggested an AAR value of 0.58 corresponding to a specific net balance of zero for the North Cascade glaciers. Paterson (1981) suggested an AAR value of 0.7 for zero mass balance for the Alpine glaciers. Most of such findings are based upon observations made either in North America or Europe.

It has been suggested that AAR representing zero mass balance would be substantially lower, i.e. less than 0.5 for the Himalayan glaciers, due to avalanche accumulation or topographic concentration (Müller, 1978). These suggestions have not yet been supported by field observations. Therefore, in this paper, a relationship is shown between AAR and mass balance for two glaciers, Gara and Gor-Garang, in Himachal Pradesh, India. By using additional data for a few more glaciers, an attempt has been made to get a general AAR value representing zero mass balance for the western Himalaya. This generalized AAR value may not be directly applicable to the eastern Himalayan glaciers located in Sikkim and Arunachal Pradesh, due to their different accumulation pattern (Kulkarni and Narain, 1990). In addition, Landsat satellite images were used to estimate mass balance for two further years.

\section{AAR and mass-balance relationship}

For Gara and Gor-Garang Glaciers, field-based estimates of mass balance and AAR are available from 1977-78 to 1982-83 and 1976-77 to 1983-84, respectively. These glaciers are located in the Satluj River basin in Himachal Pradesh, India. For both of the glaciers the relationship is

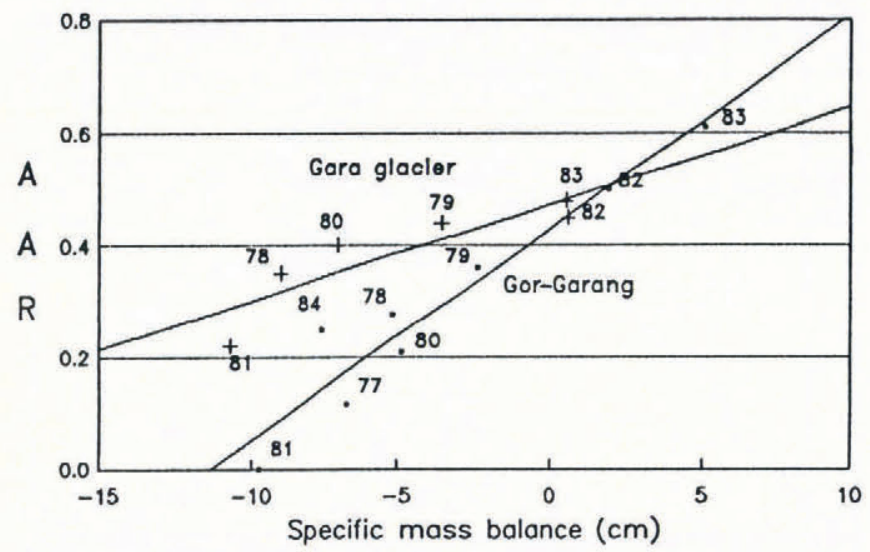

Fig. 2. Showing the relationship between $A A R$ and mass balance for Gara and Gor-Garang Glaciers. plotted in Figure 2. The regression analysis suggests a high correlation coefficient, i.e. 0.88 and 0.96 with AAR values of 0.47 and 0.43 , representing zero mass balance for Gara and Gor-Garang Glaciers, respectively.

The Landsat satellite data were used to get AAR values for the year 1986-87 and 1987-88, respectively. Landsat TM imagery dated 10 August 1987 and 17 August 1988 were used. These images for this period were selected because the glacier melting season normally ends around this time. This makes it possible to obtain the equilibrium line. The false-colour composite was enlarged to a scale of $1: 50000$ by using the high-magnification enlarger developed at the Space Applications Centre, Ahmedabad. The scale adjustment was done by using topographic maps supplied by the Survey of India (SOI). For Gara Glacier, AAR values for 1986-87 and 1987-88 are 0.57 and 0.16 , respectively. This indicates positive mass balance for the year 1986-87 and negative mass balance for 1987-88. The results are comparable with field observations made at the adjacent Chhota Shigri Glacier (Kulkarni, 1988) and snowfall data for this area (Bhakra Beas Management Board, 1988).

\section{Generalization of AAR value for the western Himalaya}

To assess a common value of AAR representing zero mass balance for the western Himalaya (west of Nepal), fieldbased AAR and mass-balance values were compiled from various sources. Data from six glaciers were available, two (Gara and Gor-Garang Glaciers) in Himachal Pradesh, three (Neh-Nar, Kolahoi and Shishram Glaciers) in Jammu and Kashmir, and one (Tipra Bank Glacier) in Uttar Pradesh. For these glaciers, except Gara and GorGarang, data are not available for a sufficient number of years to develop a relationship for the individual glaciers. Therefore, a combined relationship was established between AAR and mass balance by including data from all glaciers together (Fig. 3). This gave 22 data points from six glaciers. The regression analysis suggests a reasonably good correlation with $r$ equal to 0.75 . The AAR value representing zero mass balance is 0.44 .

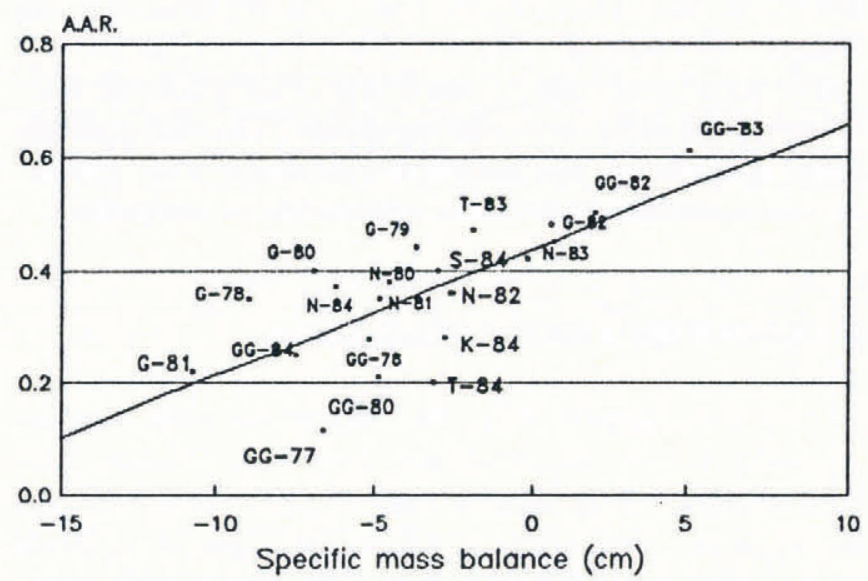

Fig. 3. Showing the relationship between $A A R$ and mass balance for the western Himalayan glaciers for different years, where T, Tipra Bank; $\mathcal{N}, \mathcal{N}$ eh-Nar; G, Gara; GG, Gor-Garang; K, Kolahoi; S, Shishram. 


\section{VARIATION IN MASS BALANCE WITH EQUIL- IBRIUM-LINE ALTITUDE (ELA)}

The equilibrium line is usually considered as the snow line at the end of the glacier melt season. A clear relationship exists between its position and the annual mass balance (Østrem, 1975; Meier and Post, 1962). Once a relationship between ELA and mass balance is established, it can be used to obtain mass balance. This can decrease the field efforts and minimize the cost in the long term. The prediction can be further improved by using additional parameters such as activity index (Pelto, 1988). For most of the Himalayan glaciers, field-based mass-balance data are not available; therefore, this method may give less accurate results (Braithwaite, 1984).

For Gor-Garang and Gara Glaciers, field measurements of equilibrium line and mass balance are available for 8 and 6 years, respectively. These are plotted in Figure 4. This gives very high correlation with $r$ of -0.94 and -0.92 for Gara and Gor-Garang Glaciers, respectively. By using this relationship, mass balance is estimated for the years 1987 and 1988. The ELA values are estimated by using satellite images and comparison with Survey of India topographic maps. ELA for Gor-Garang Glacier is $5080 \mathrm{~m}$ and $5250 \mathrm{~m}$ and for Gara Glacier it is $5080 \mathrm{~m}$ and $5340 \mathrm{~m}$ for the years $1986-87$ and $1987-88$, respectively.

A linear regression analysis suggests that the ELA for zero specific mass balance is $5095 \mathrm{~m}$ for Gor-Garang Glacier and $5154 \mathrm{~m}$ for Gara Glacier. This suggests a specific mass balance of $+0.1 \mathrm{~cm}$ for the year 1986-87 and $-1.6 \mathrm{~cm}$ for the year $1987-88$ for Gor-Garang Glacier. For Gara Glacier, it is $+3.4 \mathrm{~cm}$ and $-8.6 \mathrm{~cm}$ for the years 1986-87 and 1987-88, respectively.

\section{DISCUSSION AND CONCLUSIONS}

The accumulation area ratio value corresponding to a zero mass balance is substantially lower for the western Himalaya compared to North America and Europe. The data collected from the six Himalayan glaciers suggest an AAR value of 0.44 , corresponding to a zero mass balance.

For Gara and Gor-Garang Glaciers, very high correlation coefficients, i.e. 0.96 and 0.88 , were observed. But the correlation coefficient was reduced to 0.74 when data from six glaciers were correlated together. This suggests that, if AAR and mass-balance data are available for a glacier for a sufficient number of years, then AAR can be used to obtain mass balance. For those glaciers where historical data are not available, the AAR may not give a specific mass-balance value within acceptable limits, but correlation is still good enough to give a trend in mass balance, i.e. positive or negative, for a large number of Himalayan glaciers for which hardly any field data are available.

The AAR value for thousands of Himalayan glaciers can be obtained by using satellite images. The false-colour composite prepared from Landsat satellite images obtained diring a period between the middle of August and September can be used to obtain the AAR.

A better relationship was observed between equilibrium-line altitude and mass balance. The field data from Gara and Gor-Garang Glaciers suggest a high correlation

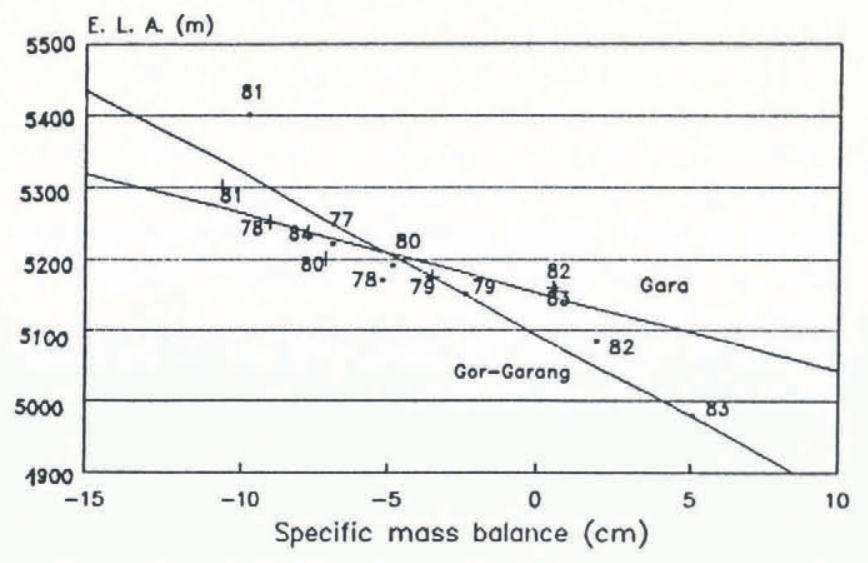

Fig. 4. Showing the relationship between ELA and mass balance for Gara and Gor-Garang Glaciers.

coefficient, i.e. -0.92 and -0.94 , respectively. The ELA values obtained from the satellite images and topographic maps suggest a positive mass balance for the year 1986-87 and a negative one for the year 1987-88.

Therefore, the results suggest that the AAR can be obtained by using a remote-sensing technique, which can also be used to obtain a trend in the mass balance for a large number of Himalayan glaciers. The ELA method can be applied to obtain the mass balance for those glaciers for which historical data are available.

\section{ACKNOWLEDGEMENTS}

The author would like to thank Drs A. Narain, R. R. Navalgund and P. Desai for their comments and suggestions.

\section{REFERENCES}

Bhakra Beas Management Board (BBMB). 1988. Snow hydrology studies in India with reference to Satluj and Beas catchment. In Workshop on Snow Hydrology, Manali, India. Section VIII.

Braithwaite, R.J. 1984. Can the mass balance of a glacier be estimated from its equilibrium-line altitude? $\mathcal{J}$. Glaciol., 30(106), 364-368.

Kaul, M. K. 1986. Mass balance of Liddar glaciers. Trans. Inst. Ind. Geogr., 8(2), 95-112.

Kulkarni, A. V. 1988. A field study of snow cover albedo on the Chota Shigri Glacier, H.P. Ahmedabad, Space Applications Centre. (Technical note No. SAC/RSA/RSAGMWRD/TN/01/88.)

Kulkarni, A. V. and A. Narain. 1990. Remote sensing based glacier inventory in the Sikkim state, presented at Regional Workshop on IRS-1A Mission and its Application Potential. Gangtok, Sikkim.

Meier, M. F. 1962. Proposed definitions for glacier mass budget terms. J. Glaciol., 4(33), 252-263.

Meier, M. F. and A. S. Post. 1962. Recent variations in mass net budgets of glaciers in western North America. International Association of Scientific Hydrology Publication 58 (Symposium at Obergurgl 1962 - Variations of Glaciers), 63-77. 
Müller, F. 1980. Present and late Pleistocene equilibrium line altitudes in the Mt Everest region - an application of the glacier inventory. International Association of Hydrological Sciences Publication 126 (Workshop at Riederalp 1978 - World Glacier Inventory), 75-94.

Østrem, G. 1975. ERTS data in glaciology - an effort to monitor glacier mass balance from satellite imagery. $\mathcal{F}$. Glaciol., 15(73), 403-415.

Paterson, W. S. B. 1981. The physics of glaciers. Second edition. Oxford, etc., Pergamon Press.
Pelto, M. S. 1988. The annual balance of North Cascade glaciers, Washington, U.S.A., measured and predicted using an activity-index method. F. Glaciol., 34(117), 194-199.

Raina, V.K., M.K. Kaul and S. Sing. 1977. Massbalance studies of Gara Glacier. F. Glaciol., 18(80), 415423.

The accuracy of references in the text and in this list is the responsibility of the author, to whom queries should be addressed.

MS received 29 August 1990 and in revised form 15 October 1991 